\title{
PENGARUH PEMBERIAN APU-APU (Pistia stratiotes $L$ ) SEBAGAIPUPUK ORGANIK DENGAN DOSIS YANG BERBEDA TERHADAP POPULASI KUTU AIR ( Daphnia sp )
}

\author{
THE EFFECT OF GIVING POPE (Pistia stratiotes $L$ ) AS A ORGANIC FERTILIZER \\ WITH DIFFERENT DOSAGE ON WATER POPULATION WATER \\ (Daphnia sp)
}

\author{
Tania Serezova Augusta \\ Aquatic Aquaculture Studies Program Faculty of Fisheries Christian University \\ Palangka Raya \\ E-mail : taniaserezova@gmail.com
}

\begin{abstract}
Abstrak
Kutu air atau bahasa latinnya (Daphnia sp) merupakan salah satu jenis pakan alami yang sangat penting untuk pakan alami ikan. Namun kutu air ini sangat jarang ditemukan jika tidak di budidayakan khususnya pada perairan tawar. Kondisi ini menyebabkan kutu air menjadi terbatas dan perlu di budidayakan. Penelitian ini bertujuan untuk mengetahui pengaruhpemberian apu-apu(Pistia stratiotes $l$ )sebagaipupuk organik dengan dosis yang berbeda terhadap populasi kutu air (Daphnia sp). Kegunaan penelitian agar memberikan informasi mengenai pengaruhpemberian apu-apu(Pistia stratiotes l)sebagaipupuk organik dengan dosis yang berbeda terhadap populasi kutuair (Daphnia sp). Penelitian ini dilaksanakan selama dua minggu yang dimulai dari tanggal 02-17 Mei2017. Penelitian dilaksanakan di LaboratoriumFakultas Perikanan Universitas Kristen Palangka Raya.Dengan metode pelaksanaan adalah : persiapan 9 (sembilan) buah aquarium untukmedia budidaya Daphnia $s p$, pembuatan pupuk organik, pemberian dosis yang berbeda masing-masing :perlakuan A : $0,25 \mathrm{gr} / \mathrm{ltr}$ air, perlakuan B : 0,50 gr/ltr air, perlakuan $\mathrm{C}: 0.75 \mathrm{gr} / \mathrm{ltr}$ air, serta pengamatan kualitas air.

Hasil penelitian menunjukkan bahwa perlakuan dosis apu-apu $(0,25) \mathrm{gr} / \mathrm{ltr}$ air, $(0,50) \mathrm{gr} / \mathrm{ltr}$ air dan $(0,75) \mathrm{gr} / \mathrm{ltr}$ airberpengaruh sangat nyata terhadap populasi kutu air. Berdasarkan uji lanjut beda nyata tektual (BNT) dengan tingkat kepercayaan 99\%,menunjukkan perlakuanA dosis $0,25 \mathrm{gr} / \mathrm{ltr}$ airlebih baik dari perlakuan B dosis $0,50 \mathrm{gr} / \mathrm{ltr}$ air dan perlakuan $\mathrm{C} 0,75 \mathrm{gr} / \mathrm{ltr}$ air dan perlakuan $0,5 \mathrm{gr} / \mathrm{ltr}$ airlebih baik dibandingkan $0,75 \mathrm{gr} / \mathrm{ltr}$ air.Rata-rata kondisi kualitas air pada pemeliharan kutu air di Aquarium antara lainDO = 5,23-5,29 ml/l, $\mathrm{pH}=6,43-7,55$, Suhu $=26,34-26,56^{\circ} \mathrm{C}$, TDS $=52,33-60,99 \mathrm{ml} / \mathrm{l}$. Parameter kualitas air sangat mendukung terhadap keberadaan populasi kutu air.
\end{abstract}

Kata kunci : Apu-Apu, Daphnia, populasi

\begin{abstract}
Water flea or Latin (Daphnia sp) is one type of natural food that is very important for natural fish feed. But this water fleas are very rare to find if not cultivated, especially in fresh water. This condition causes water fleas to be limited and need to be cultivated. This study aims to determine the effect of apu-apu (Pistia stratiotes $l$ ) as an organic fertilizer with different doses of water flea population (Daphnia $s p$ ). Usefulness of the research to provide information on the effects of apu-apu (pistia stratiotes 1) as organic fertilizer with different doses of the water flea population (daphnia sp). This research was conducted for two weeks starting from 02 - 17 May 2017. The research was conducted in the Laboratory of the Faculty of Fisheries of Palangka Raya Christian University. With the implementation method are: preparation of 9 (nine) aquarium for cultivation media of Daphnia sp, making of organic fertilizer, giving different dose respectively: treatment A:
\end{abstract}


$0,25 \mathrm{gr} / \mathrm{ltr}$ water, treatment B: $0,50 \mathrm{gr} / \mathrm{ltr}$ water, C: $0.75 \mathrm{gr} / \mathrm{ltr}$ water treatment, and water quality observation.

The results showed that the dosage of apu-apu $(0,25) \mathrm{gr} / \mathrm{ltr}$ water, $(0,50) \mathrm{gr} / \mathrm{ltr}$ water and $(0,75) \mathrm{gr} / \mathrm{ltr}$ of water had a significant effect on the water flea population. Based on further experimental test of significant difference (BNT) with $99 \%$ confidence level, showed treatment A dose $0,25 \mathrm{gr} / \mathrm{ltr}$ water better than treatment B dose $0,50 \mathrm{gr} / \mathrm{ltr}$ water and treatment $\mathrm{C} 0,75 \mathrm{gr} / \mathrm{ltr}$ water and $0.5 \mathrm{gr} / \mathrm{ltr}$ water treatment is better than 0.75 $\mathrm{g} /$ ltr water.

The average of water quality conditions in the maintenance of water fleas in Aquarium are $\mathrm{DO}=5,23-5,29 \mathrm{ml} / 1, \mathrm{pH}=6,43-7,55$, Temperature $=26,34-26,56 \mathrm{C}$, TDS $=52,33-$ $60.99 \mathrm{ml} / \mathrm{l}$. Water quality parameters strongly support the presence of water flea population.

\section{Keywords : Apu-Apu, Daphnia, population}

\section{PENDAHULUAN}

Pakan alami ialah makanan hidup bagi larva atau benih ikan dan udang. Beberapa jenis pakan alami yang sesuai untuk benih ikan air tawar, antara lain lnfusoria (Paramaecium sp.), Rotifera (Brachionus sp.),dan Daphnia sp. Pakan alami tersebut mempunyai kandungan gizi yang lengkap dan mudah dicerna dalam usus benih ikan. Ukuran tubuhnya yang relatif kecil sangat sesuai dengan lebar bukaan mulut larva/benih ikan.Pakan alami dapat dilakukan dengan menggunakan kotoran hewan kering yang ada di sekitar kita. Di kalangan petani dikenal Daphnia $s p$ dengan nama "kutu air". Jenis kutu ini mempunyai bentuk tubuh agak bulat, bergaris tengah antara $0,9-1,8 \mathrm{~mm}$ dan berwarna kemerahan (Pangkey, 2009).

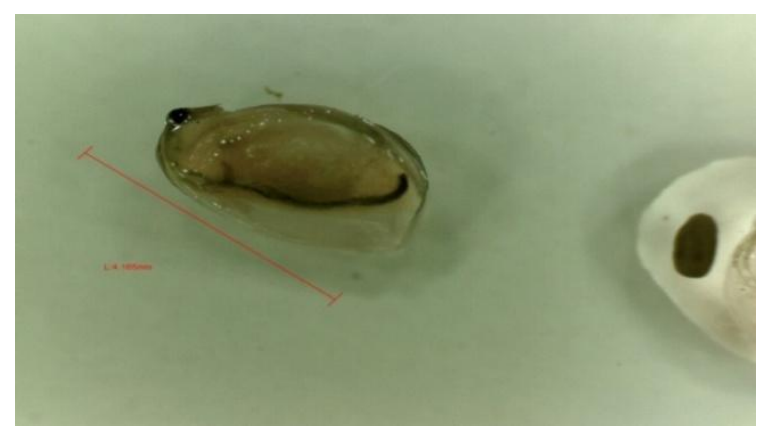

Gambar 1. Kutu Air (Daphnia sp)

Pakan alami sangat diperlukan dalam budidaya ikan dan pembenihan, karena akan menunjang kelangsungan hidup benih ikan. Pada saat telur ikan baru menetas maka setelah makanan cadangan habis, benih ikan membutuhkan pakan yang sesuai dengan ukuran tubuhnya. (Izzahdkk, 2014).

Kutu air (Daphnia sp) merupakan salah satu jenis pakan alami yang sangat 
penting untuk pakan ikan. Namun kutu air ini sangat jarang ditemukan jika tidak dibudidayakan khususnya pada perairan tawar. Kondisi ini menyebabkan kutu air menjadi terbatas dan perlu dibudidayakan. Sehingga untuk upaya pengelolaannya di perairan tawar sangat di butuhkan aspek biologi dan ekologis pada kutu air. Untuk mendapatkan data populasi mengenai kutu air maka dilakukan penelitian denganpembuatan dan pemberian pupuk organik dari apu-apu dengan dosis yang berbeda dan bahan ini masih belum pernah diolah sebelumnya .

Pupuk organik adalah pupuk yang mengandung banyak bahan organik daripada kadar hara-nya.Sumber bahan organik dapat berupa kompos, pupuk hijau, pupuk kandang, sisa panen (jerami, tongkol jagung, dan sabut kelapa), limbah ternak, limbah industri yang menggunakan bahan pertanian, dan limbah kota (sampah) tersusun dari materi makhluk hidup, seperti pelapukan sisa-

sisa tanaman, hewan, dan manusia.Pupuk organik dapat berbentuk padat atau cair yang digunakan untuk memperbaiki sifat fisik, kimia, dan biologi tanah(Syukur A, 2006).

Berdasarkan hasil penelitian Hernayati dkk (2004),bahwa apu-apu dapat dijadikan pupuk dengan dosis 0,25 mg/l untuk pertumbuhan populasi kutu air yang baik.

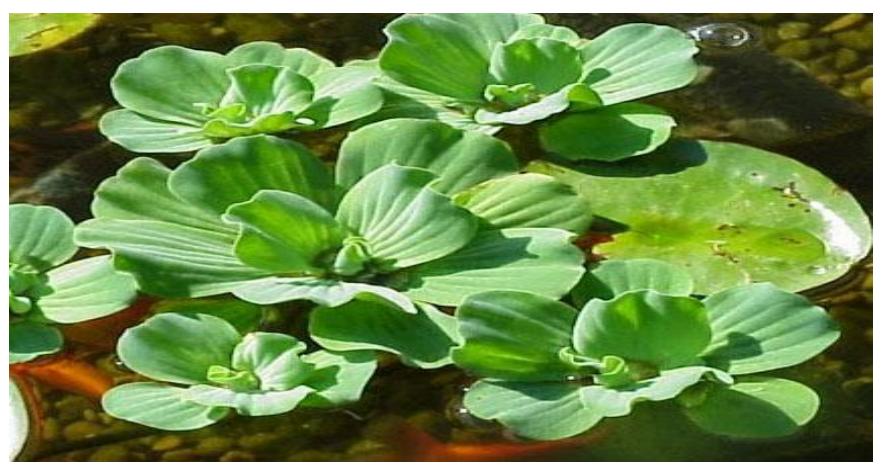

Gambar 2. Apu-apu (Pistia stratiotes L)

\section{Kualitas Air}

Daphnia sp dapat hidup pada selang suhu $18-24^{\circ} \mathrm{C}$. Selang suhu ini merupakan selang suhu optimal bagi pertumbuhan dan perkembangan Daphnia sp. Diluar selang suhu tersebut, Daphnia spakan cenderung bersifat dorman. Daphnia sp. Membutuhkan $\mathrm{pH}$ sedikit alkalin yaitu antara 6.7 sampai 9.2. Seperti halnya makhluk akuatik lainnya $\mathrm{pH}$ tinggi dan kandungan amonia tinggi dapat bersifat mematikan bagi Daphnia sp, oleh karena itu tingkat amonia perlu dijaga dengan baik dalam suatu sistem budidaya mereka. 
Ketahanan Daphnia sp yang baik pada perairan yang miskin oksigen mungkin disebabkan oleh kemampuannya mensintesis hemoglobin. Naiknya kadar haemoglobin dalam darah Daphnia sp, selain diakibatkan oleh kurangnya oksigen terlarut di perairan, juga diakibatkan oleh naiknya suhu, dan tingginya kepadatan populasi Daphnia sp. Pada kondisi dengan kadar oksigen terlarut rendah, mereka akan meningkatkan kadar haemoglobin untuk membantu pendistribusian oksigen dalam tubuh mereka. Kehadiran hemoglobin ini sering menyebabkan Daphnia sp berwarna merah. Hal ini tidak akan terjadi apabila kadar oksigen terlarut cukup (Herwanti, 2013).

Kualitas air yang ideal untuk mengkultur Daphnia $s p$ dan Moina $s p$ adalah suhu $24-26,7^{\circ} \mathrm{C}$, pH 6,4-7,5, DO di atas 3,1 mg/l dan kandungan amonia 0,008-0,144 mg/l Daphnia spdan Moina spsangat dipengaruhi oleh beberapa faktor yaitu suhu, intensitas cahaya, oksigen terlarut, salinitas, dan $\mathrm{pH}$ (Sasongko, 2014).

\section{METODE PENELITIAN}

Tabel 1. Alat dan Bahan Dalam Penelitian

\begin{tabular}{|c|l|l|}
\hline No & \multicolumn{1}{|c|}{ Alat/Bahan } & \multicolumn{1}{c|}{ Kegunaan } \\
\hline 1. & Horiba Water Checker & Untuk mengukur derajat keasaman dan kebasaan air \\
\hline 2. & Horiba Water Checker & Untuk mengukur suhu air \\
\hline 3. & Horiba Water Checker & Untuk mengukur Kandungan Oksigen dalam air \\
\hline 4. & Timbangan Digital & Untuk menimbang berat bahan penelitian \\
\hline 5. & Mikroskop Digital & Untuk mengukur ukuran tubuh kutu air \\
\hline 6. & TDS & $\begin{array}{l}\text { Untuk mengukur kandungan bahan organik terlarut dan daya } \\
\text { hantar listrik }\end{array}$ \\
\hline 7. & Aquarium & Untuk wadah pupuk organik dari apu-apu dan kutu air \\
\hline 8. & Alat tulis & Untuk mencatat data yang diperoleh \\
\hline 9. & Kamera & Untuk dokumentasi kegiatan \\
\hline 10. & Gelas ukur & Untuk melihat pertumbuhan populasi kutu air. \\
\hline 11. & Serok & Untuk tempat pengambilan Kutu Air \\
\hline 12. & Kutu air & Bahan pengamatan penelitian \\
\hline 13. & Apu-apu & Bahan pupuk organik \\
\hline
\end{tabular}

Penelitian menggunakan rancangan acak lengkap ( RAL) dengan 3 perlakuan dan 3 kali ulangan. Perlakuan adalah : Budidaya Daphnia sp dengan dosis pupuk organik yang berbeda yaitu :
Perlakuan A : 0,25 gr/l air ; Perlakuan B : 0,50 gr/l air ; Perlakuan C : 0.75 gr/l air 
Data yang diperoleh selanjutnya dianalisis ragam (ANOVA) untuk mengetahui pengaruh perlakuan yang diberikan terhadap pertumbuhan dan kelangsungan hidup kutu air (Daphnia sp). Model matematika dari perlakuan yaitu sebagai berikut : $\mathrm{Y} \mathrm{ij}=\mu+\tau \mathrm{i}+\varepsilon \mathrm{ij}$

Keterangan $\quad:$ Y ij $=$ Respon terhadap perlakuan ke $\mathrm{i}$ pada ulangan ke $\mathrm{j}$

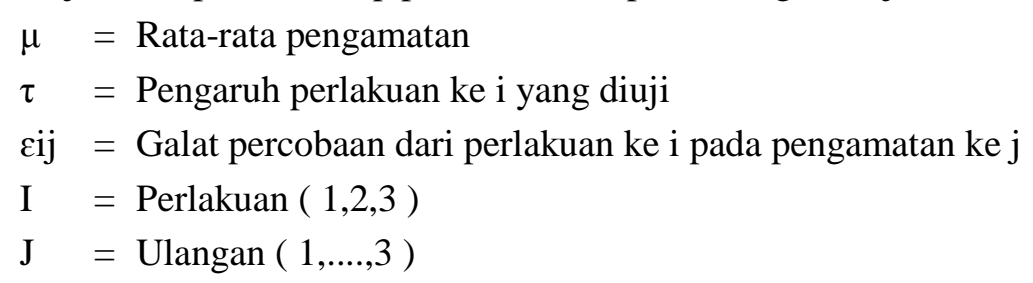

\section{Prosedur Pelaksanaan Penelitian}

Persiapan media tempat penelitian

Yang pertama dipersiapkan yaitu Aquarium yang di isi air sebanyak 20 liter dengan ukuran aquarium terdiri dari $\mathrm{P}: 40$ $\mathrm{x} \mathrm{L}$ : $30 \mathrm{~cm}$. Untuk ukuran 5 aquarium yang kecil dan P : 50 x L : $30 \mathrm{~cm}$, untuk ukuran aquarium yang besar dan di isi sebanyak 20 liter air dan di diamkan selama 2 hari.

Adapun tahap-tahap pelaksanaan penelitian adalah sebagai berikut :

Tahap I : membuat pupuk organik Apuapu dengan di keringkan selama 4 hari sampai hasilnya benar-benar kering, lalu dicincang dan ditimbang apuapu yang sudah kering kemudian ditebarkan kedalam aquarium dengan dosis $\mathrm{A}: 0,25$ gr/l, B: 0,50 gr/l dan C:0.75 gr/l.
Tahap II : Kutu air jenis (Daphnia sp), di ambil atau di beli dari pembudidaya untuk bahan pengamatan.

Tahap III : kutu air di tebarkan sebanyak 200 ekor tiap perlakuan setelah pupuk di tebarkan selama 4 hari.

Tahap IV : Selanjutnya diamati populasi kutu air, ukuran panjang pada hari awal dan akhir penelitian, Untuk melihat populasinya kutu air di hitung secara manual dan hasil yang sudah di hitung di kembalikan kedalam aquarium.

Tahap V: Penelitian kualitas air yang meliputi pH, Suhu, DO, TDS pada hari 1, 7 dan 14 .

Populasi kutu air dari jenis pupuk organik Apu-apu dan dilihat populasi paling bagus di antara jenis dosis yang 
berbeda selanjutnya hasil dokumentasi dan data yang diperoleh dicatat pada hari 1dan hari ke 14.

\section{Analisis Data}

Data yang di peroleh dilakukan penghitungan dengan analisis ragam (ANOVA) untuk melihat perbedaan popolasi kutu air melalui perhitungan.F hitung selanjutnya dibandingkan dengan nilai $\mathrm{F}$ tabel $5 \%$ dan $1 \%$. Apabila F hitung lebih besar dari $\mathrm{F}$ tabel, maka kaidah keputusan adalah tolak Ho dan terima $\mathrm{H} 1$ (berbeda nyata atau sangat nyata) sebaliknya apabila nilai $\mathrm{F}$ hitung lebih kecil dari nilai $\mathrm{F}$ tabel, maka kaidah keputusanya adalah terima Ho dan tolak H1 (tidak berbeda nyata). Jika diperoleh adanya pengaruh perlakuan, akan dilanjutkan dengan uji beda nyata terkecil (BNT) (Nurhartika, 2010).

\section{HASIL DAN PEMBAHASAN}

\section{Hasil Pengamatan Populasi kutu air}

\section{(Daphnia sp)}

Berdasarkan hasil pengamatan penelitian, populasi kutu air pada 9 (sembilan) buah aquarium yang digunakan untuk populasi kutu air sebagai berikut :

$$
\begin{aligned}
& A=0,25 \mathrm{gr} / 1 \text { air } \\
& B=0,50 \mathrm{gr} / 1 \text { air } \\
& C=0,75 \mathrm{gr} / 1 \text { air }
\end{aligned}
$$

Dalam 1 liter air dimasukkan10 ekor kutu air, sehingga dalam 20 liter dimasukkan kutu air sebanyak 200 ekor kedalam masing-masing aquarium sebanyak 9 buah aquarium.

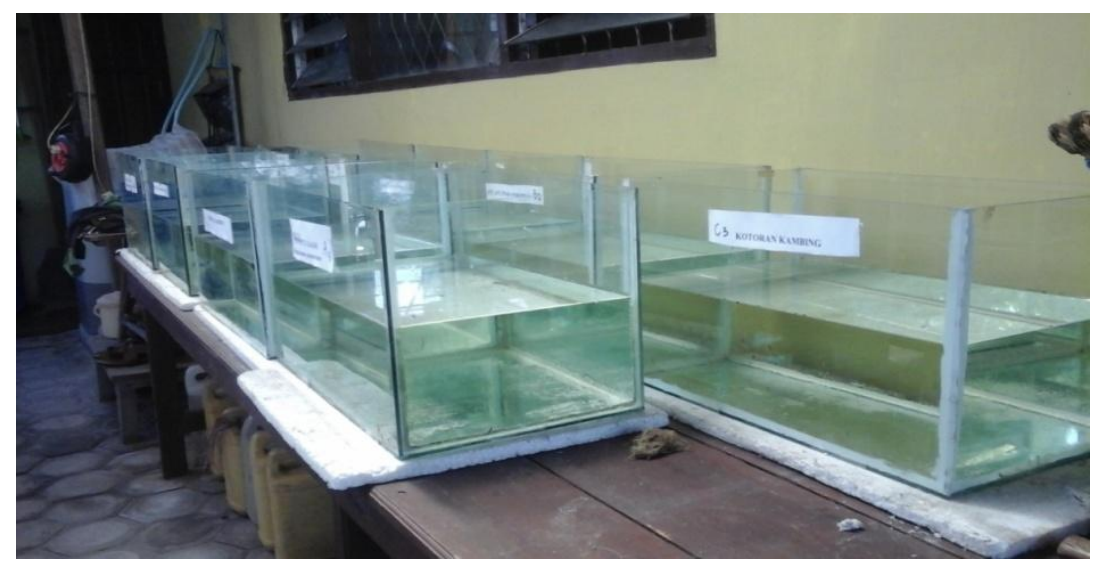

Gambar 3. Media Pemeliharaan Kutu Air 
Tabel 2. Jumlah Populasi Kutu Air di Aquarium Selama Penelitian

\begin{tabular}{|c|c|c|}
\hline Perlakuan & $\begin{array}{l}\text { Hasil Populasi kutu air } \\
\text { (Individu / Aquarium) }\end{array}$ & $\begin{array}{c}\text { Perkembangan dan penurunan populasi pada } \\
\text { kutu air }\end{array}$ \\
\hline A $: 1$. & 238 & \multirow{3}{*}{$\begin{array}{l}\text { Penambahan } 3 \text { hari berkembang baik terhadap } \\
\text { populasi }\end{array}$} \\
\hline 2. & 306 & \\
\hline 3. & 269 & \\
\hline B : 1 . & 106 & \multirow{3}{*}{$\begin{array}{l}\text { Penurunan akibat padat nya dosis apu-apu yang } \\
\text { digunakan }\end{array}$} \\
\hline 2. & 128 & \\
\hline 3. & 152 & \\
\hline $\mathrm{C}: 1$ & - & \multirow{3}{*}{$\begin{array}{l}\text { Penurunan akibat padat nya dosis apu-apu yang } \\
\text { digunakan. }\end{array}$} \\
\hline 2. & 61 & \\
\hline 3. & - & \\
\hline
\end{tabular}

Secara visual perkembangan yaitu perlakuan A: 0,25 gr/l dibandingkan populasi kutu air awal dan akhir dapat dengan perlakuan B: 0,50 gr/l dan C: 0,75 dilihat pada Tabel 2. Hasil penelitian gr/l. menyatakan bahwadosis yang paling bagus

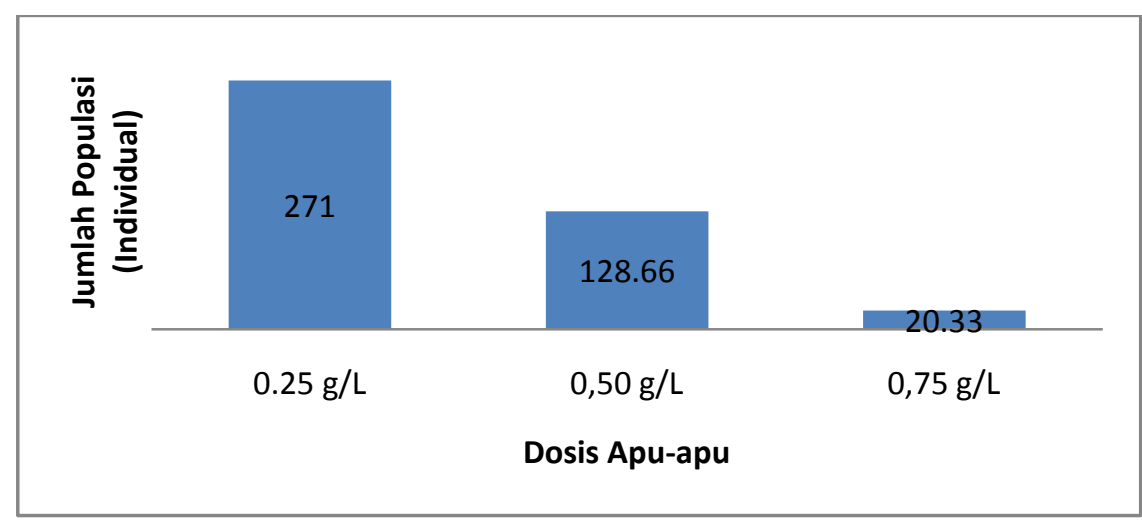

Gambar 4. Grafik Rata-rata populasi Kutu Air (Daphnia sp)

Berdasarkan Analisis ragan (ANOVA) diperoleh nilai $\mathrm{F}$ hitung $(48,57)$ $>\mathrm{F}$ tabel $(5,1433)$ atau $(10,925)$. Dengan demikian dapat disimpulkan perlakuan dosis apu-apu berpengaruh sangat nyata terhadap populasi kutu air. Berdasarkan uji lanjut beda nyata tektual (BNT) dengan tingkat kepercayaan 99\% menunjukkan perlakuan dosis 0,25 baik dari dosis 0,50 dan 0,75 , dan perlakuan 0,5 lebih baik dibandingkan 0,75 .

$$
\text { Berdasarkan populasi (Daphnia }
$$
$s p)$ terdapat senyawa dengan pengikatannya dari apu-apu. Hal ini diduga disebabkan oleh apu-apu mengandung zat bentuk 
lanvicidal atau pertumbuhan larva 0,75 gr/l berdasarkan hasil pengamatan (Shivakumar,2013)

\section{Ukuran Panjang Tubuh (Daphnia sp)}

Hasil pengukuran panjang tubuh populasi kutu air yang paling panjang dan besar bentuk ukurannya adalah pada perlakuan A dengan dosis 0,25 gr/l di bandingkan perlakuan B 0,50 gr/l dan C pada dosis perlakuan $\mathrm{B}$ dan $\mathrm{C}$ di gunakan terlalu banyak sehinga menghambat populasi kutu air (Daphnia sp) sehingga bisa dikatakan perlakuan A dengan dosis 0,25 gr yang baik untuk populasinya kutu air (Daphnia sp)dan bisa di lihat pada Gambar 5 berikut :

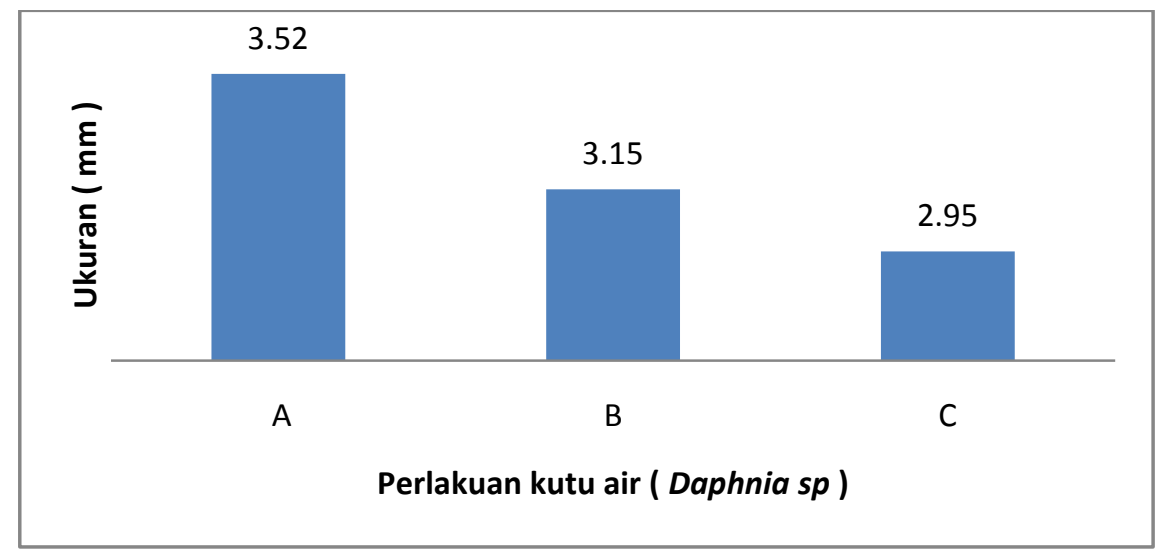

Gambar 5. Grafik Rata-rata Panjang Kutu Air (Daphnia sp)

\section{Parameter Kualitas Air}

Hasil dari pengukuran parameter kualitas air dapat di lihat pada Tabel 3 berikut.

Tabel 3: Data Rata-Rata Pengukuran Rarameter Kualitas Air Selama Penelitian

\begin{tabular}{|c|c|c|c|}
\hline \multirow{2}{*}{ Parameter } & \multicolumn{3}{|c|}{ Perlakuan (Rata-rata/kisaran nilai) } \\
\cline { 2 - 4 } & $\mathrm{A}$ & $\mathrm{B}$ & $\mathrm{C}$ \\
\hline $\mathrm{DO}(\mathrm{mg} / 1)$ & 5,23 & 4,87 & 5,29 \\
\hline $\mathrm{pH}($ skala $\mathrm{pH})$ & 7,22 & 7,18 & 7,01 \\
\hline Suhu $\left({ }^{\circ} \mathrm{C}\right)$ & 26,58 & 26,34 & 26,56 \\
\hline $\mathrm{TDS}$ & 52,33 & 54,33 & 60,99 \\
\hline
\end{tabular}

\section{DO (Oksigen Terlarut)}

Menurut Sasongko (2014)bahwa kandungan DO di aquarium yang ditoleransi olehkutu air yaitu diatas $3,1 \mathrm{mg} / \mathrm{l}$.Hasil pengukuran oksigen terlarut selama penelitian, menunjukkan bahwa kisaran DO antara 5,23-5,29 mg/1.

pH (Derajat keasaman) 
Dari hasil selama penelitian dalam populasi kutu air pHyang di peroleh adalah 6,43-7,67. Terjadi peningkatan $\mathrm{pH}$ pada hari ke 7 dan ke 14 hal ini dengan diduga berawal dari zat-zat yang melalui larut kandungan apu-apu.Menurut Sasongko(2014), pH air yang sesuai untuk populasi kutu air adalah 6,4-7,5.

\section{Suhu}

Suhu rata-rata air selama penelitian pada populasi kutu air yang di amati adalah 26.34-26,58 ${ }^{\circ} \mathrm{C}$,dan terjadi penurunan pada hari ke 14 karena suhu yang masuk kedalam perairan di aquarium menurun dan tidak panas.

Menurut Sasongko, (2014). Suhu air sangat menentukan keberhasilan dalam populasi kutu air, Suhu yang baik dan optimal untuk populasi kutu air adalah 22$30^{\circ} \mathrm{C}$.

\section{TDS}

Dari hasil pengukuran TDS (Total Dissolved Solid) yang di amati selama penelitian rata-rata 52,33-60,99, TDS juga sangat menentukan populasi kutu air, TDS biasanya disebabkan oleh bahan organik berupa ion yang terkandung dalam perairan, konsentrasi TDS di dalam perairan sangat bervariasi karena adanya nilai kelarutan mineral yang berada dalam suatu daerah geologi.
Menurut Iowa DNR (2009)letal konsentrasinya TDS untuk kutu air (Cariodaphnia dubia) $390 \mathrm{mg} / \mathrm{l}$ selama penelitian TDS masih di bawah nilai tersebut karena hanya sedikit kandungan dari zat atau mineral yang terdapat dari apu-apu.

\section{KESIMPULAN}

Hasil penelitian menunjukkan (Dahpnia sp)perlakuan dosis apu-apu $(0,25) \mathrm{gr} / \mathrm{ltr}$ air, $(0,50)$ gr/ltr air dan $(0,75) \mathrm{gr} / \mathrm{ltr}$ air berpengaruh sangat nyata terhadap populasi kutu air. Berdasarkan uji lanjut beda nyata tektual (BNT) dengan tingkat kepercayaan 99\% menunjukan perlakuan dosis 0,25gr/ltr air lebih baik dari dosis $0,50 \mathrm{gr} / \mathrm{ltr}$ air dan $0,75 \mathrm{gr} / \mathrm{ltr}$ air, dan perlakuan 0,50 gr/ltr air lebih baik dibandingkan $0,75 \mathrm{gr} / 1 \mathrm{tr}$ air

Parameter kualitas air selama pemeliharan kutu air di Aquarium antara lain Sebagai berikut :DO = 5,23-5,29 ml/l, $\mathrm{pH}=6,43$ 7,55 Suhu $=26,34-26,56^{\circ} \mathrm{C}$, TDS $=52,33-$ $60,99 \mathrm{ml} / \mathrm{l}$, kualitas air cukup layak untuk pemeliharaan kutu air.

\section{DAFTAR PUSTAKA}

Fitriani, A. 2002. Peran Pakan Alami (Daphnia sp dan Tubifex $s p$ ) terhadap SR(Kelangsungan Hidup) dan Pertumbuhan Larva Ikan Baung (Mystus nemurus) di Balai Budidaya Air Tawar 
Sukabumi. Jawa Barat.(Skripsi) Pogram Studi Budidaya Perairan Fakultas Kedokteran Hewan. Universitas Airlangga.

Hernayanti dan Proklamasiningsih, Elly, 2004. Fitoremediasi Limbah Cair Batik Menggunakan Apuapu (Pistia stratioters L) sebagai Upaya untuk Memperbaiki Kualitas Air. Fakultas Biologi UNSOED Purwokerto.

Herwanti V.E, 2013 Analisis Pemberian Daphnia sp,yang Dikultur Masal pada Media Pupuk Fermentasi terhadap Pertumbuhan Larva Ikan Gurami (Ospronemus gouramy) Fakultas Perikanan Universitas Diponegoro. Semarang.

Iowa D NR. 2009. Water Qualitiy Standards Review : Chloride, Sulfate and Total Dissolved Solods.

Izzah N, Suminto,Herawati V.E 2014. Pengaruh Bahan Organik Kotoran Ayam, Bekatul, dan Bungkil Kelapa Melalui Proses Fermentasi Bakteri Pribotik terhadap Pola Pertumbuhand dan Produksi Biomassa Daphia sp. Jurnal of Aguaculture management and Technology. Fakultas Perikanan dan 3 ( 2) : 44-52

Nurhartika, S 2010, Rancangan Acak Lengkap (RAL).Jurusan Biologi,Fakultas Matematika dan Ilmu Pengetahuan Alam, Intitut Teknologi Surabaya.

Pangkey, 2009. Klasifikasi Daphnia $s p$ Fakultas Perikanan Universitas Sumatra Utara. Medan.
Sasongko E.B,2014. Kajian Kualitas Air dan Pengunaan Sumur Gali oleh Masyarakat di Sekitar Sungai Kaliyasa Kabupaten Cilacap. Program Study Ilmu Lingkungan UNDIP.

Shivakumar RMS, Srinivasan, Natarajan D, 2013. Larvioalpoten Tial of Some Indian Medikananl Plant Extracts Aganst Aedes. Asian Jurnal Of Pharma Ceutical and Cilinical Rese Arch 6 (3): 77-80.

Syukur A, 2006. Kajian Pengaruh Pemberian Macam Pupuk Organik terhadap Pertumbuhan dan Hasil Tanaman Jahe di Inceptisol, Karanganyar. 